\title{
Desempenho de Frangos de Corte Alimentados com Dietas à Base de Milho e Farelo de Soja, com ou sem Adição de Enzimas ${ }^{1}$
}

\author{
Geferson Fischer ${ }^{2}$, João Carlos Maier ${ }^{3}$, Fernando Rutz ${ }^{3}$, Viviane Lorenzato Bermudez ${ }^{4}$
}

\begin{abstract}
RESUMO - O experimento foi conduzido com o objetivo de avaliar o efeito da inclusão de um composto multi-enzimático à base de proteases, amilases e celulases (Vegpro), adicionado na proporção de $1 \mathrm{~kg}$ para cada $200 \mathrm{~kg}$ de farelo de soja, na dieta de frangos de corte. Foram utilizados 2240 pintos, fêmeas, da marca comercial Ross, submetidos a oito tratamentos, com sete repetições. O delineamento experimental utilizado foi em blocos ao acaso, com parcelas divididas. Os tratamentos foram os seguintes: T1 (controle positivo - ração normal, sem enzima), T2 (controle negativo - ração com níveis energético, protéico e aminoacídico do farelo de soja, superestimados em 5\%, sem enzima), T3 (ração normal, sem enzima até 28 dias, com enzima de 29 a 35 dias), T4 (ração normal, sem enzima até 21 dias, com enzima de 22 a 35 dias), T5 (ração normal, com enzima), T6 (até os 28 dias, ração normal com enzima, e ração superestimada com enzima, dos 29 aos 35 dias), T7 (ração normal, com enzima até os 21 dias e ração superestimada, com enzima, do $22^{\circ}$ ao $35^{\circ}$ dia) e T8 (ração superestimada com enzima). Na primeira fase experimental, à exceção do T2, não houve diferença significativa entre os tratamentos para peso corporal médio, ganho médio de peso e consumo de ração, pois não foi observado efeito da inclusão de enzima. A conversão alimentar diferiu estatisticamente a 5\%. Na quarta semana experimental, novamente o T2 foi o único a diferir a 5\% para peso corporal médio e ganho médio de peso. Para consumo de ração e conversão alimentar, os tratamentos não diferiram significativamente. Na última semana, foram notadas as maiores diferenças entre os tratamentos. Verificou-se que a inclusão do complexo multi-enzimático não proporcionou ganhos ao desempenho de frangos de corte.
\end{abstract}

Palavras-chave: desempenho, enzimas, farelo de soja, frangos de corte, milho

\section{Performance of Broilers Fed Corn Soybean Meal Based Diets, with or without Inclusion of Enzymes}

\begin{abstract}
This study was run to evaluate the effect of inclusion of an enzymatic cocktail, containing proteases, amilases and cellulases (Vegpro) in broiler diets. The cocktail was added with the ration of $1 \mathrm{~kg}$ per $200 \mathrm{~kg}$ of soybean meal. Two thousand and forty female Ross chicks were distributed in eight treatments with seven replicates each. A split-plot experimental design was used. Treatments consisted of T1 - control (no enzyme added), T2 - diet five percent lower in energy, protein and amino acids, without enzyme addition. T3 - control (no enzyme added up to 28 days and with enzyme from 29 to 35 days of age), T4 - control (without enzyme up to 21 days and with enzyme from 22 to 35 days of age), T5 - control (plus enzyme addition), T6 - control (plus enzyme addition up to 28 days of age, and five percent lower in energy, protein and amino acids, with enzyme addition from 29 to 35 days of age). T7 - control (with enzyme addition up 21 days of age and five percent lower in energy, protein and amino acids, with enzyme from 22 to 35 days of age), and T8 - five percent lower in energy, protein and amino acids. During the first experimental period, except for T2, body weight, body weight gain and feed intake were not influenced by dietary treatments. Feed conversion and factor of production differed statistically. During the fourth week of experimental period, birds fed T2 were the only ones to differ in body weight and body weight gain. Feed intake, feed conversion and factor of production were not statistically different. During the last week of experimental period, most differences among treatments were observed. The results indicate that Vegpro enzymatic cocktail was not effective in growth performance improvement.
\end{abstract}

Key Words: chicks, corn, enzymes, performance, soybean meal

\section{Introdução}

Enzimas são proteínas globulares, de estrutura terciária ou quaternária, que agem como catalisadores biológicos, aumentando a velocidade das reações no organismo, sem serem, elas próprias, alteradas neste processo (Champe \& Harvey, 1989; Fireman \& Fireman, 1998). As enzimas digestivas têm um sítio ativo que permite suas atuações na ruptura de uma determinada ligação química (Penz Jr., 1998). Somente atuam em condições específicas de temperatura, $\mathrm{pH}$ e umidade (Bühler et al., 1998).

\footnotetext{
${ }^{1}$ Parte da dissertação de mestrado do primeiro autor, apresentada ao curso de Pós-Graduação em Zootecnia da UFPel.

2 Médico Veterinário, MSc. Av. Duque de Caxias, 336, apt. 208J, 96030-002 - Pelotas/RS. E.mail: geferson@ufpel.tche.br

3 Professores DZO/UFPel.

${ }^{4}$ Médica Veterinária, MSc. E.mail: lorenzatobermudez@bol.com.br
} 
As enzimas comercialmente produzidas são provenientes, geralmente, de bactérias do gênero Bacillus sp ou de fungos do gênero Aspergillus sp (Fireman \& Fireman, 1998), portanto, os microorganismos são a principal fonte de enzimas exógenas.

As enzimas, também conhecidas como aditivos alimentares, têm sido incorporadas aos alimentos dos animais com o propósito de melhorar o seu desempenho e, com isso, a sua rentabilidade. Tais substâncias apresentam como característica central o fato de não agirem como nutrientes (Peixoto $\&$ Maier, 1993). Até hoje, somente uma pequena fração dos componentes das dietas animais são suplementados com esses aditivos. Porém essa situação poderá mudar rapidamente assim que o desenvolvimento de novas enzimas alimentares ou novas formas de aplicação desses produtos progredir (Cousins, 1999).

Atualmente, no mercado, existem enzimas destinadas a rações para animais contendo matériasprimas alternativas (trigo, cevada e triticale) e alimentos comumente utilizados (milho e farelo de soja). Em geral, as enzimas são utilizadas na alimentação animal com dois objetivos bem definidos: complementar as enzimas que são produzidas pelo próprio animal em quantidades insuficientes (amilases e proteases); fornecer aos animais enzimas que eles não conseguem sintetizar (celulases). Com essas práticas, há redução dos efeitos negativos causados pelos polissacarídios não-amiláceos (PNA's).

Os PNA's são encontrados, principalmente, como componentes estruturais das paredes celulares dos cereais. Além de serem importantes na integridade estrutural da planta, as ligações entre PNA's e outros componentes provavelmente determinam sua atividade nutricional e digestibilidade. As ligações covalentes entre os PNA's e a lignina limitam a digestibilidade de forragens em herbívoros e, naturalmente, limitam a digestibilidade dos polissacarídios quando ingeridos por não-ruminantes. Segundo Choct (2000), os polissacarídios nãoamiláceos, na dieta de não-ruminantes, têm uma atividade anti-nutricional, a qual leva a uma pobre utilização de nutrientes.

Até pouco tempo afirmava-se que dietas à base de milho e farelo de soja não poderiam ser melhoradas pela adição de enzimas. Contrariamente ao que se pensava, a qualidade nutricional do milho não é constante, visto que seu conteúdo energético pode variar muito de uma partida para outra (Leeson et al., 1993; Hurburgh, 1994, citado por Soto-Salanova et al., 1996). A variabilidade na qualidade do milho deve-se a fatores genéticos e ambientais, aos quais somam-se as alterações causadas pelos processos de secagem e armazenagem.

Dessa forma, realizou-se este experimento com o objetivo de avaliar o efeito de um complexo multienzimático à base de protease, amilase e celulase, sobre o desempenho de frangos de corte, alimentados com rações à base de milho e farelo de soja.

\section{Material e Métodos}

O experimento foi realizado em uma grande empresa do setor avícola, na região sul do país, no final do ano 2000. Foram utilizados 2400 pintosfêmea de corte, de um dia de idade, da marca comercial Ross. Destes, após pesagem, 2240 foram alojados para a condução do experimento, com 40 aves por unidade experimental.

O processo de pesagem das aves seguiu de acordo com procedimento utilizado no Centro Nacional de Pesquisa de Suínos e Aves, como segue: as aves, após pesadas individualmente, foram separadas em caixas usadas para o transporte de pintos, segundo as categorias de peso (de grama em grama). A variação de peso corporal das aves foi de $32 \mathrm{~g}$ a $49 \mathrm{~g}$. Iniciou-se, então, a montagem do experimento pelo peso médio obtido, com a formação das unidades experimentais. Primeiramente, formaram-se as repetições um (R1) de cada tratamento. Utilizaram-se quantas categorias de peso foram necessárias. A seguir, montaram-se as repetições subseqüentes. Nesse sistema de montagem das repetições experimentais, pôde-se eliminar os pintos com excesso de peso, os muito leves, além daqueles com algum tipo de problema.

$O$ aviário experimental foi dividido internamente em três linhas de boxes (20 boxes por linha), com dimensão de 2,20 m x 2,20 m cada um, que representou uma unidade experimental. O manejo geral quanto à instalação, limpeza de equipamentos, instalação e manejo de cortinas, foi o comumente adotado em granjas de integração.

O delineamento experimental utilizado foi em blocos ao acaso, com parcelas divididas, constituído por oito tratamentos (Tabela 1) e sete repetições. O 
Tabela 1 - Programa de alimentação

Table 1 - Feed program

\begin{tabular}{|c|c|c|c|}
\hline \multirow[t]{2}{*}{$\begin{array}{l}\text { Tratamento } \\
\text { Treatment }\end{array}$} & \multicolumn{3}{|c|}{$\begin{array}{l}\text { Período de fornecimento das rações experimentais (dias) } \\
\text { Period of experimental diet feeding (days) }\end{array}$} \\
\hline & 1 a 21 & 22 a 28 & 29 a 35 \\
\hline 1 & $\begin{array}{c}\text { Controle positivo } \\
\text { Positive control }\end{array}$ & $\begin{array}{l}\text { Controle positivo } \\
\text { Positive control }\end{array}$ & $\begin{array}{c}\text { Controle positivo } \\
\text { Positive control }\end{array}$ \\
\hline 2 & $\begin{array}{l}\text { Controle negativo } \\
\text { Negative control }\end{array}$ & $\begin{array}{l}\text { Controle negativo } \\
\text { Negative control }\end{array}$ & $\begin{array}{l}\text { Controle negativo } \\
\text { Negative control }\end{array}$ \\
\hline 3 & $\begin{array}{l}\text { Controle positivo } \\
\text { Negative control }\end{array}$ & $\begin{array}{l}\text { Controle positivo } \\
\text { Negative control }\end{array}$ & $\begin{array}{l}\text { Vegpro } \\
\text { Vegpro }\end{array}$ \\
\hline 4 & $\begin{array}{l}\text { Controle positivo } \\
\text { Positive control }\end{array}$ & $\begin{array}{l}\text { Vegpro } \\
\text { Vegpro }\end{array}$ & $\begin{array}{l}\text { Vegpro } \\
\text { Vegpro }\end{array}$ \\
\hline 5 & $\begin{array}{l}\text { Vegpro } \\
\text { Vegpro }\end{array}$ & $\begin{array}{l}\text { Vegpro } \\
\text { Vegpro }\end{array}$ & $\begin{array}{l}\text { Vegpro } \\
\text { Vegpro }\end{array}$ \\
\hline 6 & $\begin{array}{l}\text { Controle positivo } \\
\text { Positive control }\end{array}$ & $\begin{array}{l}\text { Controle positivo } \\
\text { Positive control }\end{array}$ & $\begin{array}{l}\text { Vegpro + Sup } \\
\text { Vegpro } \\
\text { Vup. }\end{array}$ \\
\hline 7 & $\begin{array}{l}\text { Controle positivo } \\
\text { Positive control }\end{array}$ & $\begin{array}{l}\text { Vegpro }+ \text { Sup }^{1} \\
\text { Vegpro }\end{array}$ & $\begin{array}{l}\text { Vegpro }+ \text { Sup }^{1} \\
\text { Vegpro }\end{array}$ \\
\hline 8 & $\begin{array}{l}\text { Vegpro }+ \text { Sup }^{1} \\
\text { Vegpro }+ \text { Sup. }\end{array}$ & $\begin{array}{l}\text { Vegpro }+ \text { Sup }^{1} \\
\text { Vegpro }+ \text { Sup. }\end{array}$ & $\begin{array}{l}\text { Vegpro }+ \text { Sup }^{1} \\
\text { Vegpro }+ \text { Sup. }\end{array}$ \\
\hline
\end{tabular}

${ }^{1}$ Tratamentos em que o farelo de soja teve seus níveis de energia metabolizável, proteína bruta e aminoácidos, superestimados em $5 \%$. Treatment in witch soybean meal had its metabolizable energy levels, crude protein and aminoacids, overestimated in $5 \%$.

parâmetro utilizado para a blocagem foi o peso inicial dos pintos, com o fator semana alocado às subparcelas.

O programa alimentar constituiu-se de três fases: inicial (1 a 21 dias), crescimento (22 a 28 dias) e final ( 29 a 35 dias). Também foram utilizadas quatro dietas experimentais: controle positivo (ração normal, sem enzima), controle negativo (ração cujos níveis energético, protéico e aminoacídico do farelo de soja foram superestimados em 5\%, sem adição de enzima), Vegpro (ração normal, com enzima) e VegproSup (ração com farelo de soja superestimado em 5\%, com enzima), conforme Tabelas 2, 3 e 4 .
A inclusão da enzima nas rações experimentais seguiu recomendações do fornecedor: $1 \mathrm{~kg}$ do complexo multi-enzimático para cada $200 \mathrm{~kg}$ de farelo de soja.

As variáveis analisadas foram o peso corporal médio, ganho médio de peso, consumo semanal de ração e conversão alimentar.

Os dados foram submetidos à análise de variância pelo Sistema de Análise Estatística - SANEST (Zonta \& Machado, 1984), e no caso de diferenças significativas entre os tratamentos $(\mathrm{P}<0,05)$, as médias foram comparadas pelo teste de Tukey. 
Tabela 2 - Composição percentual das dietas experimentais da fase inicial Table 2 - Percentual composition of experimental diets in the initial phase

\begin{tabular}{|c|c|c|c|c|}
\hline \multirow[t]{2}{*}{$\begin{array}{l}\text { Ingredientes } \\
\text { Ingredients }\end{array}$} & \multicolumn{4}{|c|}{$\begin{array}{l}\text { Dietas experimentais } \\
\text { Experimental diets }\end{array}$} \\
\hline & $\begin{array}{l}\text { Controle positivo } \\
\text { Positive control }\end{array}$ & $\begin{array}{c}\text { Controle negativo } \\
\text { Negative control }\end{array}$ & $\begin{array}{l}\text { Vegpro } \\
\text { Vegpro }\end{array}$ & $\begin{array}{l}\text { Vegpro }+ \text { Sup } \\
\text { Vegpro }+ \text { Sup }\end{array}$ \\
\hline Milho & 45,25 & 48,41 & 44,90 & 48,08 \\
\hline $\begin{array}{l}\text { Corn } \\
\text { Farelo de soja } \\
\text { Soybean meal }\end{array}$ & 33,46 & 31,33 & 33,53 & 31,38 \\
\hline $\begin{array}{l}\text { Sorgo } \\
\text { Sorghum }\end{array}$ & 12,00 & 12,00 & 12,00 & 12,00 \\
\hline $\begin{array}{l}\text { Óleo vegetal } \\
\text { Soybean oil }\end{array}$ & 3,55 & 2,50 & 3,65 & 2,62 \\
\hline $\begin{array}{l}\text { Farinha de carne } \\
\text { Meat meal }\end{array}$ & 2,00 & 2,00 & 2,00 & 2,00 \\
\hline $\begin{array}{l}\text { Calcário calcítico } \\
\text { Calcitic limestone }\end{array}$ & 1,46 & 1,47 & 1,47 & 1,47 \\
\hline $\begin{array}{l}\text { Fosfato bicálcico } \\
\text { Dicalcium phosphate }\end{array}$ & 0,99 & 0,99 & 0,99 & 1,00 \\
\hline $\begin{array}{l}\text { Sal (Salt) } \\
\text { Lisina líquida }\end{array}$ & $\begin{array}{l}0,44 \\
0,29\end{array}$ & $\begin{array}{l}0,44 \\
0,29\end{array}$ & $\begin{array}{l}0,44 \\
0,29\end{array}$ & $\begin{array}{l}0,44 \\
0,29\end{array}$ \\
\hline $\begin{array}{l}\text { Liquid lysine } \\
\text { Metionina líquida }\end{array}$ & 0,27 & 0,28 & 0,28 & 0,27 \\
\hline $\begin{array}{l}\text { Liquid methionine } \\
\text { Premix mineral }^{2} \\
\text { Mineral mix }\end{array}$ & 0,11 & 0,11 & 0,10 & 0,10 \\
\hline $\begin{array}{l}\text { Anticoccidiano } 10 \% \\
\text { Anticocidial } 10 \%\end{array}$ & 0,08 & 0,08 & 0,08 & 0,08 \\
\hline $\begin{array}{l}\text { Premix vitamínico } \\
\text { Vitamin mix }\end{array}$ & 0,05 & 0,05 & 0,05 & 0,05 \\
\hline $\begin{array}{l}\text { Colina líquida } 75 \% \\
\text { Liquid choline }\end{array}$ & 0,05 & 0,05 & 0,05 & 0,05 \\
\hline $\begin{array}{l}\text { Vegpro } \\
\text { Total }\end{array}$ & 100,00 & 100,00 & $\begin{array}{r}0,17 \\
100,00\end{array}$ & $\begin{array}{r}0,17 \\
100,00\end{array}$ \\
\hline $\begin{array}{l}\text { Composição calculada } \\
\text { Calculated composition }\end{array}$ & & & & \\
\hline $\begin{array}{l}\text { Proteína bruta }(\%) \\
\text { Crude protein }\end{array}$ & 21 & 21 & 21 & 21 \\
\hline $\begin{array}{l}\text { Energia metabolizável }(\mathrm{kcal} / \mathrm{kg}) \\
\text { Metabolizable energy }\end{array}$ & 3069 & 3069 & 3069 & 3070 \\
\hline $\begin{array}{l}\text { Metionina }(\%) \\
\text { Methionine }\end{array}$ & 0,5488 & 0,5465 & 0,5491 & 0,5467 \\
\hline $\begin{array}{l}\text { Metionina }+ \text { cistina }(\%) \\
\text { Methionine }+ \text { cystine }\end{array}$ & 0,9000 & 0,9000 & 0,9000 & 0,9000 \\
\hline $\begin{array}{l}\text { Lisina }(\%) \\
\text { Lysine }\end{array}$ & 1,2800 & 1,2800 & 1,2801 & 1,2798 \\
\hline $\begin{array}{l}\text { Treonina }(\%) \\
\text { Threonine }\end{array}$ & 0,8062 & 0,8037 & 0,8064 & 0,8037 \\
\hline $\begin{array}{l}\text { Triptofano }(\%) \\
\text { Tryptophan }\end{array}$ & 0,2428 & 0,2403 & 0,2430 & 0,2404 \\
\hline $\begin{array}{l}\text { Cálcio }(\%) \\
\text { Calcium }\end{array}$ & 1,0019 & 0,9982 & 1,0020 & 0,9986 \\
\hline $\begin{array}{l}\text { Sódio }(\%) \\
\text { Sodium }\end{array}$ & 0,1903 & 0,1902 & 0,1903 & 0,1902 \\
\hline
\end{tabular}

${ }^{1}$ Tratamentos em que o farelo de soja teve seus níveis de energia metabolizável, proteína bruta e aminoácidos, superestimados em $5 \%$ (Treatment in which soybean meal had its metabolizable energy levels, crude protein and aminoacids overestimated in 5\%).

2 Inclusão/t (Inclusion/t) $1 \mathrm{~kg}$. Conteúdo por kg de premix (Content per kg mix): ferro (iron) $132.143 \mathrm{mg}$; cobre (cupper) $100.000 \mathrm{mg}$; zinco (zinc) $137.000 \mathrm{mg}$; cobalto (cobalt) $2381 \mathrm{mg}$; iodo (iodine) $2308 \mathrm{mg}$; manganês (manganese) $440.000 \mathrm{mg}$; veículo q.s.p. (inert filler).

${ }^{3}$ Inclusão/t (Inclusion/t) 0,50 kg. Conteúdo por kg de premix (Content per kg mix): vit. A 40.000 mg; vit. D3 $8000 \mathrm{mg}$; vit. E 160.000 mg; vit. K3 8000 mg; vit. B1 4.040 mg; vit. B2 15.000 mg; vit. B6 8080 mg; vit. B12 40.000 mg; biotina (biotin) 12.000 mg; ác. fólico (folic acid) 2100 mg; ác. pantotênico (pantothenic acid) 21.700 mg; niacina (niacin) 80.800 mg; selênio (selenium) 1300 mg; antioxidante (antioxidant) 200 g; promotor de crescimento (growth promoter) 140 g; veículo q.s.p. (inert filler). 
Tabela 3 - Composição percentual das dietas experimentais da fase de crescimento Table 3 - Percentual composition of experimental diets in the growing phase

\begin{tabular}{|c|c|c|c|c|}
\hline \multirow[t]{2}{*}{$\begin{array}{l}\text { Ingredientes } \\
\text { Ingredients }\end{array}$} & \multicolumn{4}{|c|}{$\begin{array}{l}\text { Dietas experimentais } \\
\text { Experimental diets }\end{array}$} \\
\hline & $\begin{array}{c}\text { Controle positivo } \\
\text { Positive control }\end{array}$ & $\begin{array}{c}\text { Controle negativo } \\
\text { Negative control }\end{array}$ & $\begin{array}{l}\text { Vegpro } \\
\text { Vegpro }\end{array}$ & $\begin{array}{c}\text { Vegpro }+ \text { Sup }^{1} \\
\text { Vegpro }+ \text { Sup } \\
\end{array}$ \\
\hline Milho & 33,38 & 34,89 & 33,93 & 35,36 \\
\hline $\begin{array}{l}\text { Corn } \\
\text { Farelo de soja } \\
\text { Soybean meal }\end{array}$ & 15,98 & 14,95 & 14,87 & 13,90 \\
\hline $\begin{array}{l}\text { Sorgo } \\
\text { Sorghum }\end{array}$ & 30,00 & 30,00 & 30,00 & 30,00 \\
\hline $\begin{array}{l}\text { Farelo de arroz integral } \\
\text { Integral rice meal }\end{array}$ & 5,00 & 5,00 & 5,00 & 5,00 \\
\hline $\begin{array}{l}\text { Óleo de soja } \\
\text { Soybean oil }\end{array}$ & 3,78 & 3,27 & 3,55 & 3,07 \\
\hline $\begin{array}{l}\text { Farinha de carne } \\
\text { Meat meal }\end{array}$ & 3,86 & 3,89 & 4,87 & 4,88 \\
\hline $\begin{array}{l}\text { Farinha de penas } \\
\text { Feather meal }\end{array}$ & 3,00 & 3,00 & 3,00 & 3,00 \\
\hline $\begin{array}{l}\text { Farinha de visceras } \\
\text { Poultry by product }\end{array}$ & 3,00 & 3,00 & 3,00 & 3,00 \\
\hline $\begin{array}{l}\text { Calcário calcítico } \\
\text { Calcitic limestone }\end{array}$ & 0,88 & 0,87 & 0,58 & 0,58 \\
\hline $\begin{array}{l}\text { Sal (Salt) } \\
\text { Lisina líquida }\end{array}$ & $\begin{array}{l}0,35 \\
0,39\end{array}$ & $\begin{array}{l}0,35 \\
0,39\end{array}$ & $\begin{array}{l}0,34 \\
0,39\end{array}$ & $\begin{array}{l}0,35 \\
0,40\end{array}$ \\
\hline $\begin{array}{l}\text { Liquid lysine } \\
\text { Metionina líquida }\end{array}$ & 0,16 & 0,16 & 0,17 & 0,16 \\
\hline $\begin{array}{l}\text { Liquid methionine } \\
\text { Premix mineral }^{2} \\
\text { Mineral mix }\end{array}$ & 0,08 & 0,08 & 0,08 & 0,08 \\
\hline $\begin{array}{l}\text { Anticoccidiano } 12 \% \\
\text { Anticocidial } 12 \%\end{array}$ & 0,06 & 0,06 & 0,06 & 0,06 \\
\hline $\begin{array}{l}\text { Premix vitamínico } \\
\text { Vitamin mix }\end{array}$ & 0,05 & 0,05 & 0,05 & 0,05 \\
\hline $\begin{array}{l}\text { Colina líquida } \\
\text { Liquid choline }\end{array}$ & 0,03 & 0,04 & 0,03 & 0,04 \\
\hline $\begin{array}{l}\text { Vegpro } \\
\text { Total }\end{array}$ & 100,00 & 100,00 & $\begin{array}{r}0,08 \\
100,00\end{array}$ & $\begin{array}{r}0,07 \\
100,00\end{array}$ \\
\hline $\begin{array}{l}\text { Composição calculada } \\
\text { Calculed composition }\end{array}$ & & & & \\
\hline $\begin{array}{l}\text { Proteína bruta }(\%) \\
\text { Crude protein }\end{array}$ & 19 & 19 & 19 & 19 \\
\hline $\begin{array}{l}\text { Energia metabolizável ( } \mathrm{kcal} / \mathrm{kg}) \\
\text { Metabolizable energy }\end{array}$ & 3220 & 3220 & 3220 & 3220 \\
\hline $\begin{array}{l}\text { Metionina }(\%) \\
\text { Methionine }\end{array}$ & 0,4302 & 0,4292 & 0,4333 & 0,4323 \\
\hline $\begin{array}{l}\text { Metionina }+ \text { cistina }(\%) \\
\text { Methionine }+ \text { cystine }\end{array}$ & 0,8200 & 0,8200 & 0,8200 & 0,8200 \\
\hline $\begin{array}{l}\text { Lisina }(\%) \\
\text { Lysine }\end{array}$ & 1,0998 & 1,1002 & 1,1000 & 1,1000 \\
\hline $\begin{array}{l}\text { Treonina }(\%) \\
\text { Threonine }\end{array}$ & 0,7299 & 0,7289 & 0,7257 & 0,7245 \\
\hline $\begin{array}{l}\text { Triptofano }(\%) \\
\text { Tryptophan }\end{array}$ & 0,1883 & 0,1871 & 0,1843 & 0,1832 \\
\hline $\begin{array}{l}\text { Cálcio }(\%) \\
\text { Calcium }\end{array}$ & 0,9471 & 0,9482 & 0,9506 & 0,9501 \\
\hline $\begin{array}{l}\text { Sódio }(\%) \\
\text { Sodium }\end{array}$ & 0,1902 & 0,1903 & 0,1903 & 0,1903 \\
\hline
\end{tabular}

${ }^{1}$ Tratamentos em que o farelo de soja teve seus níveis de energia metabolizável, proteína bruta e aminoácidos, superestimados em $5 \%$ (Treatment in which soybean meal had its metabolizable energy levels, crude protein and aminoacids overestimated in $5 \%$.)

2 Inclusão/t (Inclusion/t) 0,85 kg. Conteúdo por kg de premix (Content per kg mix): ferro (iron) $132.143 \mathrm{mg}$; cobre (cupper) $100.000 \mathrm{mg}$; zinco (zinc) $13.7000 \mathrm{mg}$; cobalto (cobalt) 2381mg; iodo (iodine) $2308 \mathrm{mg}$; manganês (manganese) $440.000 \mathrm{mg}$; veículo q.s.p. (inert filler).

${ }^{3}$ Inclusão/t (Inclusion/t) 0,50 kg. Conteúdo por kg de premix (Content per kg mix): vit. A 32.000 mg; vit. D3 7000 mg; vit. E 120.000 mg; vit. K3 $6000 \mathrm{mg}$; vit. B1 $4040 \mathrm{mg}$; vit. B2 $11.250 \mathrm{mg}$; vit. B6 $6060 \mathrm{mg}$; vit. B1240.000 mg; biotina (biotin) 10.000 mg; ác. fólico (folic acid) $1050 \mathrm{mg}$; ác. pantotênico (pantothenic acid) 17.400 mg; niacina (niacin) 60.600 mg; selênio (selenium) 1100 mg; antioxidante (antioxidant) 200 g; promotor de crescimento (growth promoter) 80 g; veículo q.s.p. (inert filler). 
Tabela 4 - Composição percentual das dietas experimentais da fase final

Table 4 - Percentual composition of experimental diets in the final phase

\begin{tabular}{|c|c|c|c|c|}
\hline \multirow[t]{2}{*}{$\begin{array}{l}\text { Ingredientes } \\
\text { Ingredients }\end{array}$} & \multicolumn{4}{|c|}{$\begin{array}{l}\text { Dietas experimentais } \\
\text { Experimental diets }\end{array}$} \\
\hline & $\begin{array}{c}\text { Controle positivo } \\
\text { Positive control }\end{array}$ & $\begin{array}{c}\text { Controle negativo } \\
\text { Negative control }\end{array}$ & $\begin{array}{l}\text { Vegpro } \\
\text { Vegpro }\end{array}$ & $\begin{array}{c}\text { Vegpro + Sup } \\
\text { Vegpro }+ \text { Sup }\end{array}$ \\
\hline $\begin{array}{l}\text { Milho } \\
\text { Corn }\end{array}$ & 35,36 & 36,86 & 35,19 & 36,69 \\
\hline $\begin{array}{l}\text { Farelo de soja } \\
\text { Soybean meal }\end{array}$ & 15,70 & 14,69 & 15,73 & 14,73 \\
\hline $\begin{array}{l}\text { Sorgo } \\
\text { Sorghum }\end{array}$ & 30,00 & 30,00 & 30,00 & 30,00 \\
\hline $\begin{array}{l}\text { Óleo de soja } \\
\text { Soybean oil }\end{array}$ & 3,94 & 3,45 & 4,00 & 3,50 \\
\hline $\begin{array}{l}\text { Farelo de arroz integral } \\
\text { Integral rice oil }\end{array}$ & 5,00 & 5,00 & 5,00 & 5,00 \\
\hline $\begin{array}{l}\text { Farinha de carne } \\
\text { Meat meal }\end{array}$ & 4,97 & 4,97 & 4,97 & 4,97 \\
\hline $\begin{array}{l}\text { Farinha de penas } \\
\text { Feather meal }\end{array}$ & 3,50 & 3,50 & 3,50 & 3,50 \\
\hline $\begin{array}{l}\text { Calcário Calcítico } \\
\text { Calcitic limestone }\end{array}$ & 0,63 & 0,63 & 0,63 & 0,63 \\
\hline $\begin{array}{l}\text { Sal (Salt) } \\
\text { Lisina líquida }\end{array}$ & $\begin{array}{l}0,38 \\
0,22\end{array}$ & $\begin{array}{l}0,38 \\
0,22\end{array}$ & $\begin{array}{l}0,38 \\
0,22\end{array}$ & $\begin{array}{l}0,38 \\
0,22\end{array}$ \\
\hline $\begin{array}{l}\text { Liquid lysine } \\
\text { Metionina líquida }\end{array}$ & 0,14 & 0,14 & 0,14 & 0,14 \\
\hline $\begin{array}{l}\text { Liquid methionine } \\
\text { Premix mineral }^{2} \\
\text { Mineral mix }\end{array}$ & 0,05 & 0,05 & 0,05 & 0,05 \\
\hline $\begin{array}{l}\text { Premix vitamínico } \\
\text { Vitamin mix }\end{array}$ & 0,05 & 0,05 & 0,05 & 0,05 \\
\hline $\begin{array}{l}\text { Colina líquida } 75 \% \\
\text { Liquid choline }\end{array}$ & 0,06 & 0,06 & 0,06 & 0,06 \\
\hline $\begin{array}{l}\text { Vegpro } \\
\text { Total }\end{array}$ & 100,00 & 100,00 & $\begin{array}{r}0,08 \\
100,00\end{array}$ & $\begin{array}{r}0,08 \\
100,00\end{array}$ \\
\hline $\begin{array}{l}\text { Composição calculada } \\
\text { Calculed composition }\end{array}$ & & & & \\
\hline $\begin{array}{l}\text { Proteína bruta }(\%) \\
\text { Crude protein }\end{array}$ & 18 & 18 & 18 & 18 \\
\hline $\begin{array}{l}\text { Energia met. }(\mathrm{kcal} / \mathrm{kg}) \\
\text { Metabolizable energy }\end{array}$ & 3250 & 3250 & 3250 & 3250 \\
\hline $\begin{array}{l}\text { Metionina (\%) } \\
\text { Methionine }\end{array}$ & 0,3849 & 0,3840 & 0,3852 & 0,3841 \\
\hline $\begin{array}{l}\text { Metionina + Cistina }(\%) \\
\text { Methionine + cystine }\end{array}$ & 0,7499 & 0,7500 & 0,7501 & 0,7501 \\
\hline $\begin{array}{l}\text { Lisina }(\%) \\
\text { Lysine }\end{array}$ & 0,9497 & 0,9498 & 0,9502 & 0,9504 \\
\hline $\begin{array}{l}\text { Treonina }(\%) \\
\text { Threonine }\end{array}$ & 0,6942 & 0,6930 & 0,6945 & 0,6934 \\
\hline Triptofano (\%) & 0,1765 & 0,1753 & 0,1766 & 0,1754 \\
\hline $\begin{array}{l}\text { Cálcio }(\%) \\
\text { Calcium }\end{array}$ & 0,8471 & 0,8465 & 0,8490 & 0,8483 \\
\hline $\begin{array}{l}\text { Sódio }(\%) \\
\text { Sodium }\end{array}$ & 0,1898 & 0,1898 & 0,1899 & 0,1899 \\
\hline
\end{tabular}

${ }^{1}$ Tratamentos em que o farelo de soja teve seus níveis de energia metabolizável, proteína bruta e aminoácidos, superestimados em $5 \%$ (Treatment in which soybean meal had its metabolizable energy levels, crude protein and aminoacids overestimated in $5 \%$ ).

${ }^{2}$ Inclusão/t (Inclusion/t) 0,50 kg. Conteúdo por kg de premix (Content per kg mix): ferro (iron) $132.143 \mathrm{mg}$; cobre (cupper) $100.000 \mathrm{mg} ; \mathrm{zinco}$ (zinc) $137.000 \mathrm{mg}$; cobalto (cobalt) $2.381 \mathrm{mg}$; iodo (iodine) $2.308 \mathrm{mg}$; manganês (manganese) 440.000 mg; veículo q.s.p. (inert filler).

${ }^{3}$ Inclusão/t (Inclusion/t) 0,50 kg. Conteúdo por kg de premix (Content per kg mix): vit. A 16.000 mg; vit. D 4000 mg; vit. E 80.000 mg; vit. K3 6000 mg; vit. $B_{1} 2020 \mathrm{mg}$; vit. $B_{2} 6250 \mathrm{mg}$; vit. $B_{6} 3030 \mathrm{mg}$; vit. $B_{12} 15.000 \mathrm{mg}$; biotina (biotin) $5000 \mathrm{mg}$; ác. fólico (folic acid) 1050 mg; ác. pantotênico (pantothenic acid) $10.800 \mathrm{mg}$; niacina (niacin) $40.400 \mathrm{mg}$; selênio (selenium) $660 \mathrm{mg}$; antioxidante (antioxidant) $200 \mathrm{~g}$; veículo q.s.p. (inert filler) 
Tabela 5 - Peso corporal médio semanal de 1 a 35 dias de idade

Table 5 - Body weight from 1 to 35 of age

\begin{tabular}{lllllll}
\hline & PM1 $^{1}$ & PM7 & PM14 & PM21 & PM28 & PM35 \\
\hline T1 $^{2}$ & 40,7 & 140,5 & 370,7 & $725,7^{\mathrm{a} 3}$ & $1138,5^{\mathrm{a}}$ & $1611,7^{\mathrm{a}}$ \\
T2 $^{2}$ & 40,7 & 136,2 & 352,4 & $687,8^{\mathrm{b}}$ & $1098,9^{\mathrm{b}}$ & $1549,3^{\mathrm{b}}$ \\
T3 & 40,7 & 140,9 & 371,8 & $732,5^{\mathrm{a}}$ & $1139,5^{\mathrm{a}}$ & $1612,1^{\mathrm{a}}$ \\
T4 & 40,7 & 139,1 & 367,2 & $725,3^{\mathrm{a}}$ & $1127,3^{\mathrm{ab}}$ & $1589,7^{\mathrm{a}}$ \\
T5 & 40,7 & 143,9 & 372,1 & $733,2^{\mathrm{a}}$ & $1133,9^{\mathrm{a}}$ & $1605,5^{\mathrm{a}}$ \\
T6 & 40,6 & 140,1 & 371,8 & $732,9^{\mathrm{a}}$ & $1142,1^{\mathrm{a}}$ & $1611,1^{\mathrm{a}}$ \\
T7 & 40,5 & 139,6 & 366,0 & $725,8^{\mathrm{a}}$ & $1133,1^{\mathrm{a}}$ & $1601,6^{\mathrm{a}}$ \\
T8 & 40,6 & 139,2 & 364,6 & $715,7^{\mathrm{ab}}$ & $1124,7^{\mathrm{ab}}$ & $1589,6^{\mathrm{a}}$ \\
\hline
\end{tabular}

${ }_{1}^{1}$ Peso médio (Average weight).

2 Tratamento (Treatment).

${ }^{3}$ Médias com letras distintas na mesma coluna indicam diferenças significativas $(P<0,05)$ pelo teste Tukey (Means, within a column, followed by different letter, differ $[P<.05]$ by Tukey test).

\section{Resultados e Discussão}

\section{Peso corporal médio}

Houve efeito significativo $(\mathrm{P}<0,05)$ dos tratamentos sobre o peso corporal médio. Contudo, quando os dados foram submetidos ao teste de Tukey para médias de tratamentos, esse efeito somente foi observado a partir da terceira semana de experimentação (Tabela 5).

Nas três semanas finais, somente o tratamento dois demonstrou ser estatisticamente diferente dos demais, em nível de 5\%. Tal resultado pode ser explicado pelo fato do tratamento ser o de controle negativo. Por esse motivo, era esperado que as aves arraçoadas com essa ração obtivessem peso menor, em comparação àquelas dos outros tratamentos, no transcorrer do experimento.

Ao comparar os tratamentos em que o complexo multi-enzimático foi acrescido à ração normal, com o controle positivo, percebeu-se que não houve diferença estatística. Nesse caso, não foi possível notar efeito positivo com a adição da enzima, uma vez que as aves arraçoadas com essas rações obtiveram desempenho semelhante.

O controle negativo, quando comparado ao tratamento oito, em que a enzima foi acrescida durante todo o período experimental à ração superestimada, não demonstrou diferença estatística na terceira e quarta semanas. Somente na última semana de experimentação esses tratamentos foram diferentes estatisticamente.

Contudo, as aves arraçoadas com o tratamento oito, em comparação com aquelas alimentadas com o tratamento controle positivo, apresentaram diferença negativa de aproximadamente 40 gramas na última semana. Esse fato deve ser considerado, uma vez que as empresas do setor avícola trabalham com milhões de aves mensalmente e pequenas diferenças podem representar economia ou prejuízo.

Tais resultados são semelhantes aos obtidos por Ebert et al. (2000), que, em experimento realizado com frangos de corte, testando dois níveis energéticos, com ou sem a inclusão do complexo enzimático Vegpro, concluíram que seus efeitos são pequenos e perceptíveis apenas em ambiente de estresse térmico. Contudo, os autores notaram pequena melhora na conversão alimentar das aves submetidas ao tratamento com enzima, na primeira semana de idade.

Ganho médio de peso

$\mathrm{O}$ efeito significativo $(\mathrm{P}<0,05)$ dos tratamentos somente pôde ser observado a partir da terceira semana. Esses dados concordam com os resultados obtidos por Schang et al. (1997). Os referidos autores não observaram diferença estatística no ganho de peso aos 21 e 53 dias de idade, em experimento que estudou a inclusão do composto multi-enzimático Vegpro. As rações foram formuladas à base de milho e farelo de soja, visando atender 100 e $90 \%$ das necessidades energéticas e aminoacídicas de frangos de corte. Somente aos 42 dias de idade, os frangos apresentaram diferença estatística $(\mathrm{P}<0,05)$ quanto ao ganho de peso.

Novamente, nas três últimas semanas de experimentação, o tratamento dois mostrou-se estatisticamente diferente dos demais, exceto em relação ao tratamento oito, aos 21 e 28 dias (Tabela 6).

Pôde-se comprovar que o tratamento controle

Tabela 6 - Ganho médio de peso dos 7 aos 35 dias de idade Table 6 - Body weight gain from 7 to 35 of age

\begin{tabular}{lrlllr}
\hline & GP7 $^{1}$ & GP14 & GP21 & GP28 & GP35 \\
\hline T1 $^{2}$ & 99,8 & 330,0 & $685,0^{\mathrm{a} 3}$ & $1097,8^{\mathrm{a}}$ & $1571,0^{\mathrm{a}}$ \\
T2 $^{2}$ & 95,5 & 311,6 & $647,1^{\mathrm{b}}$ & $1058,2^{\mathrm{b}}$ & $1508,5^{\mathrm{b}}$ \\
T3 & 100,2 & 331,1 & $691,8^{\mathrm{a}}$ & $1098,7^{\mathrm{a}}$ & $1571,4^{\mathrm{a}}$ \\
T4 & 98,3 & 326,4 & $684,5^{\mathrm{a}}$ & $1086,5^{\mathrm{a}}$ & $1548,9^{\mathrm{a}}$ \\
T5 & 103,2 & 331,4 & $692,5^{\mathrm{a}}$ & $1093,2^{\mathrm{a}}$ & $1564,7^{\mathrm{a}}$ \\
T6 & 99,5 & 331,1 & $692,3^{\mathrm{a}}$ & $1101,5^{\mathrm{a}}$ & $1570,5^{\mathrm{a}}$ \\
T7 & 99,1 & 325,4 & $685,2^{\mathrm{a}}$ & $1092,5^{\mathrm{a}}$ & $1561,0^{\mathrm{a}}$ \\
T8 & 98,6 & 324,0 & $675,1^{\mathrm{ab}}$ & $1084,1^{\mathrm{ab}}$ & $1548,9^{\mathrm{a}}$ \\
\hline
\end{tabular}

1 Ganho de peso (Body weight gain).

${ }^{2}$ Tratamento (Treatment).

3 Médias com letras distintas na mesma coluna indicam diferenças significativas $(P<0,05)$ pelo teste Tukey (Means, within a column, followed by different letter, differ $[P<.05]$ by Tukey test). 
Tabela 7 - Consumo de ração dos 7 aos 35 dias de idade Table 7 - Feed intake from 7 to 35 days of age

\begin{tabular}{lllllc}
\hline & GP7 $^{1}$ & GP14 & GP21 & GP28 & GP35 \\
\hline T1 $^{2}$ & 129,9 & 360,6 & $567,5^{\mathrm{ab} 3}$ & 764,4 & $1002,1^{\mathrm{bc}}$ \\
T2 $^{\mathrm{b}}$ & 137,8 & 342,9 & $545,7^{\mathrm{b}}$ & 737,8 & $965,2^{\mathrm{d}}$ \\
T3 & 132,9 & 356,9 & $577,3^{\mathrm{ab}}$ & 756,1 & $1001,1^{\mathrm{bc}}$ \\
T4 & 133,0 & 362,5 & $581,3^{\mathrm{a}}$ & 762,2 & $983,9^{\mathrm{cd}}$ \\
T5 & 139,9 & 365,6 & $590,1^{\mathrm{a}}$ & 759,8 & $994,2^{\mathrm{bcd}}$ \\
T6 & 127,7 & 355,8 & $577,6^{\mathrm{ab}}$ & 761,8 & $1082,3^{\mathrm{a}}$ \\
T7 & 129,2 & 357,0 & $572,3^{\mathrm{ab}}$ & 763,5 & $1022,3^{\mathrm{b}}$ \\
T8 & 133,1 & 362,2 & $583,1^{\mathrm{a}}$ & 768,9 & $1068,3^{\mathrm{a}}$ \\
\hline
\end{tabular}

${ }^{1}$ Consumo de ração (Feed intake).

2 Tratamento (Treatment).

${ }^{3}$ Médias com letras distintas na mesma coluna indicam diferenças significativas $(\mathrm{P}<0,05)$ pelo teste Tukey (Means, within a column, followed by different letter, differ [P<.05] by Tukey test).

positivo (sem enzima) e os tratamentos cuja enzima foi adicionada à ração normal somente na última semana do experimento, não diferiram entre si estatisticamente. Apesar disso, o controle positivo se manteve sempre entre os melhores resultados, enquanto o tratamento oito, por exemplo, onde a enzima foi adicionada desde o primeiro dia experimental em ração superestimada, obteve, ao término do experimento, o segundo pior desempenho. Levando-se em consideração uma empresa que abate milhões de aves mensalmente, este fato torna-se relevante, apesar de não ter havido diferença estatística.

Apesar disso, ao comparar-se o tratamento dois (ração superestimada sem enzima) com o tratamento oito (ração superestimada com enzima), pôde-se notar que as aves arraçoadas com este último tratamento obtiveram desempenho superior. Mesmo assim, este resultado é muito aquém do controle positivo.

Em um experimento utilizando ração à base de milho e farelo de soja, superestimando os níveis protéico e energético em 7\%, Pereira (1998) concluiu que as aves obtiveram ganho de peso superior àquelas aves arraçoadas com uma ração padrão (normal).

\section{Consumo de ração}

Os efeitos referentes aos tratamentos foram significativos somente a partir da terceira semana de experimentação (Tabela 7). Na primeira, segunda e quarta semanas de vida das aves, o consumo de ração não variou significativamente $(\mathrm{P}>0,05)$ entre os tratamentos. Porém, na terceira semana o tratamento dois diferiu em relação aos tratamentos quatro, cinco e oito, pois o consumo de ração das aves alimentadas com a ração controle negativo foi inferior ao das demais. Além disso, as aves submetidas ao tratamento oito foram as que consumiram a segunda maior quantidade de ração.

$\mathrm{Na}$ última semana de experimentação, ocorreram diferenças significativas $(\mathrm{P}<0,05)$ mais visíveis. $\mathrm{O}$ tratamento controle positivo foi estatisticamente diferente do tratamento oito, cuja ração superestimada foi acrescida de enzima durante todo o período experimental. Além disso, as aves alimentadas com esse último tratamento foram as que tiveram o segundo maior consumo de ração. Tal fato comprova que a adição do complexo multi-enzimático testado não supriu a superestimação dos níveis protéico, energético e aminoacídico do farelo de soja.

Testando dois níveis energéticos, com ou sem adição do complexo Vegpro, Ebert et al. (2000) concluíram que, aos 42 dias de experimentação, não houve efeito da inclusão da enzima. Por outro lado, dietas com baixa energia (superestimadas) resultaram em um maior consumo de ração pelas aves.

Stanley et al. (1998), arraçoando pintos de poedeiras comerciais até a idade de postura (24 semanas), concluíram que o consumo de ração foi significativamente menor $(\mathrm{P}<0,05)$, quando comparado ao de aves alimentadas sem enzima $(3,98 \mathrm{~kg}$ versus $4,02 \mathrm{~kg}$ ).

\section{Conversão alimentar}

Pôde-se observar que houve efeito significativo $(\mathrm{P}<0,05)$ dos tratamentos sobre a conversão alimentar. Os dados, quando submetidos ao teste de Tukey (Tabela 8), demonstraram diferença significativa $(\mathrm{P}<0,05)$ entre os tratamentos, na primeira e na última semana experimental.

Tabela 8 - Conversão alimentar dos 7 aos 35 dias de idade Table 8 - Feed:gain ratio from 7 to 35 of age

\begin{tabular}{lccccc}
\hline & CA7 $^{1}$ & CA14 & CA21 & CA28 & CA35 \\
\hline T1 $^{2}$ & $0,924^{\mathrm{b} 3}$ & 1,323 & 1,458 & 1,601 & $1,753^{\mathrm{b}}$ \\
T2 $^{2}$ & $1,012^{\mathrm{a}}$ & 1,364 & 1,492 & 1,606 & $1,762^{\mathrm{b}}$ \\
T3 & $0,942^{\mathrm{b}}$ & 1,317 & 1,457 & 1,600 & $1,752^{\mathrm{b}}$ \\
T4 & $0,955^{\mathrm{ab}}$ & 1,350 & 1,485 & 1,631 & $1,776^{\mathrm{ab}}$ \\
T5 & $0,971^{\mathrm{ab}}$ & 1,358 & 1,494 & 1,636 & $1,775^{\mathrm{ab}}$ \\
T6 & $0,911^{\mathrm{b}}$ & 1,301 & 1,448 & 1,597 & $1,804^{\mathrm{ab}}$ \\
T7 & $0,926^{\mathrm{b}}$ & 1,329 & 1,458 & 1,608 & $1,776^{\mathrm{ab}}$ \\
T8 & $0,956^{\mathrm{ab}}$ & 1,358 & 1,506 & 1,643 & $1,834^{\mathrm{a}}$ \\
\hline
\end{tabular}

1 Consumo de ração (Feed intake).

2 Tratamento (Treatment).

${ }^{3}$ Médias com letras distintas na mesma coluna indicam diferenças significativas $(P<0,05)$ pelo teste Tukey (Means, within a column, followed by different letter, differ $[P<.05]$ by Tukey test). 
Na primeira semana, a pior conversão alimentar foi registrada no tratamento dois. Apesar de não haver diferença significativa quanto ao consumo de ração entre os tratamentos, na primeira semana experimental, as aves arraçoadas com esta ração (tratamento dois) desenvolveram menor peso corporal do que quando submetidas aos outros tratamentos, motivo pelo qual registrou-se a pior conversão alimentar.

As aves arraçoadas com a ração superestimada contendo enzima desde o primeiro dia de vida (tratamento oito) alcançaram a pior conversão alimentar na última semana experimental. Nesse caso, houve diferença estatística em relação aos controles positivo e negativo. Esse fato pode significar que a enzima não propiciou o incremento energético e protéico esperado, fazendo com que as aves consumissem mais ração, com o objetivo de satisfazer as suas necessidades energéticas e protéicas.

Esses resultados foram semelhantes aos encontrados por Pereira (1998), que, com o objetivo de avaliar o efeito da adição do complexo Vegpro na ração de frangos de corte, utilizou-se de uma ração padrão (normal) e uma ração cujos níveis protéicos e energéticos haviam sido superestimados em $7 \%$. O pesquisador concluiu que as aves arraçoadas com enzima alcançaram uma conversão alimentar pior do que aquelas alimentadas com a ração padrão.

Schang et al. (1997) não encontraram diferença significativa para conversão alimentar, aos 52 dias de idade, ao fornecerem uma ração à base de milho e farelo de soja, formulada para atender 100 e $90 \%$ das necessidades energéticas e aminoacídicas de frangos de corte.

\section{Conclusões}

A inclusão do complexo multi-enzimático Vegpro, em rações à base de milho e farelo de soja, não proporcionou ganhos no desempenho de frangos de corte. O desenvolvimento das aves alimentadas com a ração superestimada em $5 \%$ nos seus níveis protéico, energético e aminoacídico, com a inclusão desse aditivo alimentar, não se igualou ao daquelas arraçoadas com ração sem enzima.

\section{Literatura Citada}

BÜHLER, M.; LIMPER, J.; MÜLLER, A. et al. Las enzimas en la nutrición animal. 1.ed. Bonn: AWT, 1998. 47p.

CHAMPE, P.C.; HARVEY, R.A. Enzimas. In: _. Bioquímica ilustrada. 2.ed. São Paulo: Artes Médicas, 1989. p.53-66.
CHOCT, M. Enzymes in animal nutrition: the unseen benefits. Capturado em 20 nov. 2000. Online. Disponível na Internet http://www.idrc.ca/books/focus/821/chp5.html.

COUSINS, B. Enzimas na nutrição de aves. In: SIMPÓSIO INTERNACIONAL ACAV - EMBRAPA SOBRE NUTRIÇÃO DE AVES, 1., 1999, Concórdia, SC. Anais... Concórdia: EMBRAPA-CNPSA, 1999. p.115-129.

EBERT, A.R.; KESSLER, A.M.; PENZ JR. et al. Effect of adding Vegpro ${ }^{\circledR}$ in two energy level diets on the performance of broilers exposed to heat stress. Poultry Science, v.79, S1, p. 19, 2000.

FIREMAN, F.A.T.; FIREMAN, A.K.B.A.T. Enzimas na alimentação de suínos. Ciência Rural, v.28, n.1, p.173-178, 1998.

PEIXOTO, R.R.; MAIER, J.C. Aditivos. In: _. Nutrição e alimentação animal.2.ed. Pelotas: EDUCAT/UFPel, 1993. p. 125-130.

PENZ Jr., A.M. Enzimas em rações para aves e suínos. In: REUNIÃO ANUAL DA SOCIEDADE BRASILEIRA DE ZOOTECNIA, 35., 1998, Botucatu. SIMPÓSIO SOBRE ADITIVOS NA PRODUÇÃO DE RUMINANTES E NÃORUMINANTES. Anais... Botucatu: Sociedade Brasileira de Zootecnia, 1998. 398p. p.165-178.

PEREIRA, A.S. Response to Allzyme Vegpro in a broiler diet with soy energy, protein and amino acids adjusted by $7 \%$ or added on top at a standart diet. In: BIOTECHNOLOGY IN THE FEED INDUSTRY. ALLTECH'S ANNUAL SYMPOSIUM, 14., 1998, Nottingham. Poster... Nicholasville: Corporate Media Services, 1999. [CD-ROM]

SCHANG, M.J.; AZCONA, J.O.; ARIAS, J.E. The performance of broilers fed with diets containing Allzyme Vegpro. In: BIOTECHNOLOGY IN THE FEED INDUSTRY. ALLTECH'S ANNUAL SYMPOSIUM, 13., 1997, Nottingham. Proceedings... Nicholasville : Corporate Media Services, 1997. [CD-ROM]

STANLEY, V.G.; ROBINSON, J.; VAUGHN, V. Growth performance, egg, size, production and feed consumption of pullets fed dietary protease enzyme. Poultry Science, v.77, p.111, 1998. (Abstract)

SOTO-SALANOVA, M. F.; GARCIA, O.; GRAHAM, H. et al. Uso de enzimas em dietas de milho e soja para frangos de corte. In: CONFERÊNCIA APINCO'96 DE CIÊNCIA E TECNOLOGIA AVÍCOLAS, 1996, Curitiba, PR. Anais... Curitiba, 1996. p.71-76.

ZONTA, E.P.; MACHADO, A.A. Sistema de análise estatística para microcomputadores - SANEST. Pelotas: Embrapa-UFPel, 1984. 